\title{
Annual Meeting of the Science Masters' Association
}

$\mathrm{T}$ HE thirty-third annual meeting of the Science Masters' Association was held on January 3-6 at the University of Bristol. The programme consisted almost entirely of a number of lectures given by the heads of various departments of the Faculty of Science of the University. In addition, a large number of visits were arranged, including a very popular one to Clifton College, where the Science School was inspected.

In his presidential address, Prof. A. M. Tyndall, director of the Henry Herbert Wills Physical Laboratory, made a departure from the traditional form in that he gave what was virtually an experimental lecture on "Gaseous Ions". His aim was to avoid a highly specialised discourse on some physical topic in an endeavour to claim the attention of the biologists, while still maintaining the interest of the physicists by a judicial selection of experiments. For the most part, his demonstrations were performed with the most simple apparatus in order to provide material which might be easily adapted to school conditions. $\mathrm{He}$ illustrated the methods of production of ions by means of coloured powders and soap bubbles, the phenomena of conduction, and the variation of velocity of movement of ions with their radius. Of historical interest was the reproduction of an experiment of about 1740 due to Abbé Nollet. An electrostatic charge was conveyed by thermal ions, produced by the flames of two candles, along a piece of wood, from a Wimshurst machine to an insulated ball, which, on receiving the charge, attracted small particles of paper from the surroundings. After a group of demonstrations on high-speed ions and their ionising power, Prof. Tyndall discussed shortly current theories regarding the nature of cosmic rays. Their existence in the room, despite the lead roof, was shown by a process of magnification by a Geiger counter and a three-stage amplifier. A series of sharp notes on a loud speaker proclaimed their arrival. During a brief survey of the causes of atmospheric electricity, he performed an experiment supporting the old Simpon theory, and appropriately concluded with his "attempt at lightning" which he demonstrated last year to the "children's auditory" at the Royal Institution.

Prof. W. E. Garner, Leverhulme professor of physical chemistry in the University, lectured on the "Decomposition and Detonation of Solids". $\mathrm{He}$ pointed out that only in exceptional cases is the liberation of gas from the interior of a crystalline lattice possible. Such a fact is in agreement with the calculations of Kossel and Stranski, who have shown that reaction centres should occur chiefly on the edges and surfaces of a solid. Decomposition results in the formation of a new interface, and it is found that the rate of reaction is proportional to its area in irreversible processes, where there is no impedance by the products. 'This is illustrated in the case of lead azide and in endothermic changes generally. The reaction takes place when one ion absorbs sufficient energy to set it in vibration and so allow it to pass its energy to other ions by collision. The detonation wave is probably caused by four adjacent azide ions decomposing simultaneously. With lead styphnate and barium azide there is, in contrast, an initial induction period and decomposition occurs throughout the whole mass of the crystal. The change, which follows a simple exponential law here, is a chain reaction with infinite chain length, and whereas detonation can only occur when the decomposition is accelerated, with lead azide it may take place at any stage of the reaction.

Prof. Sutton Pippard, professor of civil engineering, deliberately chose a comprehensive title for his talk, "The Contribution of Science in the Development of Aeronautics", in order that he might depict how the progress of aviation has depended solely on the close co-operation of science and practical engineering. The combination of the worker in pure science, who has no interest in practical results but can assimilate something of the engineer's outlook, and the engineer, who can appreciate the value of theoretical considerations and experimental research and give them some tangible form, has been a most powerful and happy one. From the inception to the first flight, advanced mathematical analysis and accurate experimental work must always be in contact. While admitting such a debt to science, Prof. Pippard emphasised, however, that the development not only in the theory of structures and elasticity, but also in meteorology, archæological research and geographical survey, has resulted in no small measure from the study of aeronautics.

In his lecture on "Neuro Humoral Mechanisms", Prof. R. J. Brocklehurst, professor of physiology, showed that in several instances the results of nerve activity can be adequately explained by postulating the liberation of a chemical substance which intermediates between the nerve and the tissue which it innervates. Loewi has demonstrated the probability of acetyl choline appearing in the heart after vagal stimulation and Lewis has brought forward evidence that a vaso-dilator substance, a histamine-like compound, is produced locally at nerve endings in the cutaneous blood vessels on antidromic stimulation or as a result of local axon reflexes. It is this substance, and not the injurious agent in a mechanical manner, which stimulates the sensory nerve endings. Prof. Brocklehurst is to be congratulated on his choice of subject since it is becoming one of increasing importance, but as yet has found no place in current physiological textbooks.

"The Geology of the Bristol District" was the subject of a lecture by Prof. S. H. Reynolds, professor of geology. Besides possessing all formations with the exception of the Archæan, Ordovician, Permian or Tertiary, the district is fortunate in having two of the finest sections of carboniferous limestone (in the Avon Gorge and at Burrington Combe) to be found in Europe, or possibly the world. A special feature in the Mendips is the way modern erosion has reproduced most of the pre-Triassic topography.

So popular was the address given by Prof. M. W. Travers on "The Discovery of the Rare Gases" that many members were required to stand until further accommodation had been provided. Only three phases of the story were related-the discovery of argon and the separation and isolation of neon. Interest was enhanced by the many personal reminiscences, and by lantern slides showing the laboratories and apparatus used in the original research.

The lecture demonstration of Dr. S. H. Piper on "Laboratory Vacuum Technique" was concerned with modern developments and the methods now used, since such facts are more accessible to universities than to schools. He dealt particularly with the 
alloy- and metal-glass seals now available, and prophesied the general use of low vapour pressure hydrocarbon oils, as prepared by Birch, in diffusion pumps. The demonstrations were of great beauty and special mention may be made of three-the method of preparing electrostatic screens in vacuo by distillation of metallic silver, the renewal of alkali metal traps by passing sodium ions electrolytically through soda glass, and finally the use of magnesium as a 'getter', the distillation being effected by means of electron bombardment.

The concluding address, the subject of which had been puzzling members for some time, was given by Dr. MacGregor Skene on "Charles and Erasmus". $\mathrm{He}$ was referring to Erasmus Darwin and his famous grandchild, who still remains, said Dr. MacGregor Skene, the greatest and best protagonist of his evolutionary theory.

The trade exhibition of apparatus and books was held in the Physies Department. There were many examples of good workmanship, especially the epidiascopes, which were displayed to full advantage in the optical laboratories. The bakelite cases for balance weights were interesting. Of outstanding interest was the display of the cycle film by Messrs. Dance-Kaufmann. This formed the subject of a demonstration and discussion initiated by Mr. H. E. Dance. The value of such films was at once apparent in the illustration of the theory of wave motion, and of the three-phase induction motor. An advantage is that only one effect is illustrated at a time, hence the teacher never loses control due to excessive detail, as is often the case in documental films. The projectors, equally adaptable to continuous and stationary films, may be operated by hand, or, in the more expensive model, by an electric motor, and can be used in daylight. The conditions of the demonstration were, throughout, those likely to be found in the class-room. The manufacturers are desirous of producing additional films of an educational type and wish to have the co-operation of science masters in editing these.

The conference, which by general agreement had been one of the most successful of recent years, ended fittingly with a tour to Cheddar in most glorious weather.

\section{Lectures at the Physical Society's Exhibition*}

\section{Measurement of Surface Tensions}

$\mathrm{T}$ HE first of the evening discourses associated with the Physical Society's twenty-third annual exhibition at the Imperial College of Science and Technology was delivered on January 3 by Dr. Allan Ferguson on "Surface Tension and its Measurement". Simple illustrative experiments were appealed to in order to demonstrate the existence of a surface tension in liquid films and surfaces, and the variation of this tension with temperature and with the nature of the liquid. Conditions of instability were illustrated experimentally, and it was pointed out that a knowledge of the quantitative laws governing these phenomena, together with an appeal to the principle of minimum potential energy, would go far to elucidate otherwise obscure phenomena.

Of the quantitative laws, the power law connecting surface tension and temperature, and Macleod's law connecting surface tension and density, together with the law of rectilinear diameters, give formulæ which represent very closely the temperature variation of liquid and vapour density, and of free and total molecular surface energy.

Conditions of drop formation were demonstrated and the formation of aniline drops in water was shown by projection, and also by means of a slow motion cinematograph film. The impact on a solid surface of an aniline drop in water was also demonstrated cinematographically, as were some of Worthington's results for the impact of liquid drops on liquid and solid surfaces.

A brief discussion was given of the principal methods for the measurement of surface tension. Simple conditions for the production and photographic measurement of large flat bubbles were reviewed, and it was pointed out that the method can be successfully used for the measurement of interfacial tensions.

Quantitative determinations of the surface tension of benzene were made by the capillary rise method, by means of the pull on a plate, and finally, by a

* The lectures are being published in the February issue of the Journal of Scientific Instruments. method which involves the use of no more than a few cubic millimetres of liquid, a knowledge of its density being unnecessary. The methods were in each instance so arranged as to be direct-reading on scales visible to the audience.

\section{Cathode Ray Osolllography}

Mr. R. A. Watson Watt's lecture on January 4 at the Physical Society's Exhibition touched on a variety of aspects of cathode ray oscillography. He referred to 'domesticated oscillograms', the electrically-recorded gramophone record and the sound-track on the 'talkie' film, as illustrating the problems and limitations of oscillography, and then proceeded to discuss the special merits of the cathode ray oscillograph. It provides a radical solution of the opposing requirements of low inertia and high photographic effect which face the designer of mechanical oscillographs, it has an exceptionally high overload capacity, and the highvoltage type is ultimately limited in speed of operation only by the errors due to the finite time of transit of the indicating electrons through the deflecting field produced by the E.M.F's under examination.

Mr. Watson Watt showed slides of oscillograms, one delineating wave trains of frequency 25 million per second, corresponding to a wireless wave-length of 12 metres, and another of still higher frequency phenomena in which a trace described in $10^{-9}$ sec. the time taken for light to travel $30 \mathrm{~cm}$.- -was clearly recorded. In this latter case the electron velocity in the recording jet was about half that of light, the transverse writing speed about one-fifth that of light.

Turning to the low-speed sealed-off oscillograph, Mr. Watson Watt enumerated the residual defects, mainly due to the gas content utilised as an aid to focusing, which still mar slightly the remarkably fine performance of modern tubes of this simple character.

The lecture was illustrated by demonstrations using eight oscillographs in all, a battery of five in parallel arranged around the lecture theatre, and three independent tubes of special construction. A demonstration of particular interest was the optical projection, throughout all the experiments, of the 